\title{
Currículo e formação de professores de História: uma alegoria
}

Curriculum and History teacher's formation: an allegory

Maria do Carmo Martins*

\section{Resumo}

Este artigo refere-se às contribuições dos estudos curriculares para o ensino de história, considerando que as pesquisas sobre esse ensino, quando perpassadas por questões curriculares, necessitam de aproximações com teorias e abordagens educacionais. Nele reflito sobre disputas acadêmicas para definição dos conteúdos de ensino, sobre a especificidade da disciplina histórica escolar e sobre a possibilidade de modificarmos a formação de professores de história, visando abordagens sobre cultura e educação planejadas pelos estudos curriculares. 0 texto foi construído como uma alegoria, partindo do quadro do pintor Terniers, o moço, intitulado $O$ arquiduque Leopoldo Guilherme em sua galeria de pinturas em Bruxelas, pertencente ao Museu do Prado, em Madri.

Palavras-Chave: Currículos; Ensino de História; Conhecimento Histórico Escolar; Formação de Professores; Pesquisa e Práticas Educacionais

\section{Abstract}

This paper refers to the contributions of the curricular studies for the teaching of history, considering that researches on this teaching, when passed by curricular questions, need approaches with educational theories and boardings. In this article I present a reflection over the academic disputes for the definition of contents of education, over the specificity of historical discipline in school and over the possibility of modifying the formation of history teachers, aiming at boardings about culture and education designed by curricular studies. The text was constructed as an allegory, parting from the picture of the painter Terniers, the Younger, entitled The archduke Leopold Wilhelm in his painting gallery at Brussels, belonging to the museum of Prado, in Madrid.

Keywords: Curriculum; Teaching of History; Historical Knowledge; Teacher Formation; Educational Research and Practices

Profa. Dra. da Faculdade de Educação da UNICAMP; membro do Grupo de Pesquisa Memória, História, Educação, e Coordenadora do Centro de Memória da Educação da FE/UNICAMP (Campinas/Brasil). carminha@unicamp.br. 
Construí este texto levando em conta a possibilidade de dialogar especialmente com historiadores e educadores, sobre as relações entre história e currículo, procurando construir uma alegoria ${ }^{1}$ para deixar clara a forma como venho entendendo a contribuição dos estudos curriculares para as pesquisas e as práticas de ensino da disciplina histórica. ${ }^{2}$

Tenho em mente aqui o quadro O Arquiduque Leopoldo Guillerme em sua galeria de pinturas em Bruxelas, do pintor Terniers, o moço, um destacado pintor da arte flamenga do século XVII. Terniers possui uma série de outros quadros que retratam as galerias de arte do período, que eram locais de colecionador, e também locais para comercialização de trabalhos.

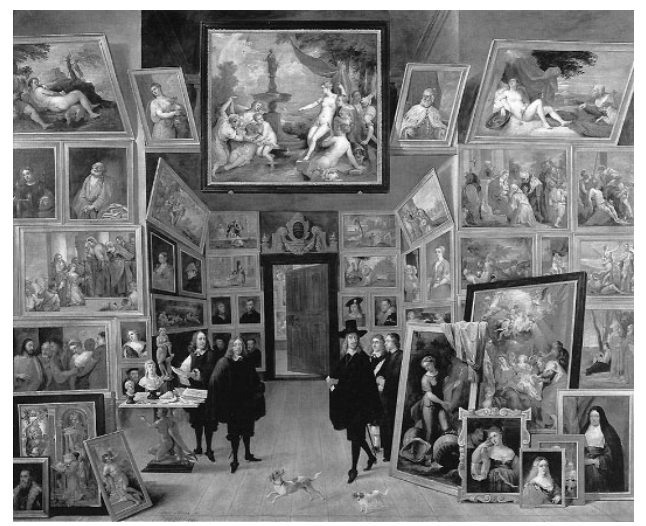

FIGURA 1: O arquiduque Leopoldo Guilherme em sua galeria de pinturas em Bruxelas Fonte: COSTA CLAVELL, Xavier. Museo del Prado - Pintura Extranjera, [s.d]. p. 89.

A obra tem como tema a apresentação da referida galeria de pinturas, com uma sala principal e paredes recobertas com quadros, que dão destaque para diversos temas e formas que compunham as muitas obras que ali se encontravam. São mostradas ainda algumas pessoas em visita à galeria,

1 Tomo alegoria no sentido do simbolismo concreto que abrange uma narrativa, em que a cada elemento do símbolo corresponda um elemento, significado ou simbolizado.

2 A primeira versão deste artigo foi apresentada como conferência no VII Encontro Nacional dos Pesquisadores do Ensino de História - ENPEH, realizado na UFMG, em fevereiro de 2006. 
dois cachorrinhos que circulam livremente pelo salão e, ademais, uma outra sala, que entrevemos apenas num relance através de uma porta semiaberta, em cujas paredes estão também outras pinturas. Assim, por inspiração dessa imagem, o presente texto foi composto de pequenas reflexões, que apresento como pequenos quadros, visando construir uma imagem do que penso hoje serem questões para debate e uma agenda para pesquisadores direcionados para as temáticas da educação e da história. A divisão em "pequenos quadros" também se justifica porque acredito ser mais importante apresentar aos poucos alguns resultados de minhas pesquisas sobre o tema Currículo e sobre a maneira a partir da qual a produção de conhecimento a seu respeito nos permite refletir sobre o saber histórico escolar em diferentes variáveis.

\section{O QUADRo e 0 PINTOR - CONTEÚdos}

Além do arquiduque e dos visitantes, vemos o próprio pintor na galeria. Podemos inclusive dizer que o quadro faz referência à própria trajetória de Terniers-como pintor oficial da corte de Bruxelas, após 1651, e que está em parte, como um detalhe, retratada em um quadro dentro do quadro. A imagem, que num primeiro olhar satura a visão do observador, ostenta a enorme produção pictórica da coleção e certo aspecto de sua exposição "desorganizada". Sugere que algumas pinturas merecem destaque aos olhos do observador (não somente pelo tamanho, mas pelo lugar que ocupam nas paredes). Sugere ainda, com a porta aberta, centralizada no fundo da imagem, que outra quantidade dessa produção está pouco visível, em sala que não é retratada. Há poucas esculturas na galeria, e elas estão concentradas sobre a mesa na frente do pintor. Temos, aqui, uma alegoria sobre a elevação da pintura como arte e da arte como produtora de sentidos culturais e sociais na modernidade. Temos, portanto, uma expressão do papel social do pintor e de sua enorme capacidade de dizer sobre seu ofício, selecionar como melhor fazê-lo e representar algo com esse discurso.

Vale dizer que esse quadro, entendido alegoricamente, nos apresenta uma forma de conceber o conhecimento e os saberes como cumulativos, e que, para melhor interpretá-los, faz-se necessário fixar o olhar em cada ponto, a fim de perceber que o que nele predomina é mais do que apenas uma listagem de coisas importantes (por exemplo, um modelo ou um estilo de pintura). Acumula-se em quantidade e também em variedade. Nesse 
sentido, no capitalismo, o saber é também passível de ser contabilizado, valorizado, legitimado. Embora consigamos perceber um predomínio temático e estilo pictórico, vale observar a pintura, buscando superar uma certa curiosidade e saturação que a profusão das imagens nos causa. Cabe registrar que não me parece casual que, em dias atuais, o quadro esteja exposto num museu grandiloqüente e profundamente "didatizado" como é o Museu do Prado, que de certa forma reproduz um pouco essa premissa do colecionador que vemos na obra de Terniers.

O que me interessa então nesse quadro não é, evidentemente, a análise de cada elemento da obra, mas sua alegoria, como forma de exposição do conhecimento. Interessa também como uma alegoria curricular, porque expressa, em alguma medida, um percurso e uma seleção de conhecimentos e saberes prescritos ao observador do quadro - pessoas, cenários, roteiros que ele deve conhecer através das pinturas - e que correspondem também às coisas centrais e/ou periféricas que devem ser conhecidas e que são legitimadas socialmente, bem como àquilo que deve ocupar lugar de destaque dentre esses saberes e àquilo que eles produzem e reproduzem na cultura da época.

Quando estudamos currículos escolares relacionados a um componente curricular específico (nesse caso, a disciplina de história), pensamos especialmente nos saberes do ensino e em sua seleção, que no código lingüístico curricular é quase sempre associada à seleção de conteúdo; nas funções sociais e nos objetivos que queremos alcançar com essa seleção e com sua aprendizagem; nos tempos e nos espaços de realização do ensino e aprendizagem desses conteúdos (a seqüência dos conteúdos e a organiżação estrutural dos saberes); nas formas e maneiras como esses conteúdos são desenvolvidos por agentes distintos (especialmente professores e alunos) com as questões da didática e das práticas do ensino); e pensamos, finalmente, nos resultados dessa aprendizagem, com o recente predomínio das questões de avaliação.

Recentemente, e em função da lógica das mudanças que se estabeleceram nas políticas educacionais, buscamos compreender também o contexto de produção dos documentos curriculares oficiais e, não raras vezes, agimos como autores e/ou críticos desses documentos, fazendo a nossa própria política do conhecimento, dentro do âmbito científico. Eu diria que este tem sido o foco predominante nas pesquisas sobre currículo em ensino de história, o que está de acordo com a alegoria do currículo como percurso. 
Em relação ao quadro de Terniers, que me inspira, diria que essa visão ampla corresponde ao percurso que o pintor estabelece quando nos direciona o olhar para as obras maiores, as pessoas e até mesmo para a luxuosidade que impera no ambiente. Ao mesmo tempo, mostra o currículo pessoal do pintor, o status do colecionador e os olhos atentos e espantados dos visitantes diante de tamanha galeria, dizendo o que vale mais e o que vale menos ali. No centro do quadro, destaca-se ainda um brasão de família sobre a porta entreaberta, indicando a nobreza dos donos do palácio onde se localiza a galeria. Assim, quando observamos a pintura realizada por Terniers, não somente a quantidade de quadros da coleção nos causa um certo impacto e direciona o nosso olhar, mas também a posição de destaque dada ao dono da coleção, aos visitantes que o acompanham, ao pintor responsável por aquela produção e à enorme quantidade de coisas para ver, que parecem não caber mais no espaço da pintura. A profusão das coisas se destaca num primeiro olhar, para logo deixar todas um pouco parecidas umas com as outras. Mas, apesar de uma certa desordem, tudo ali está de tal forma exposto que a posição de cada quadro nas paredes parece dar a eles um jeito de importância, como se todos fossem belos, valiosos e possuíssem motivo prévio para estar ali. É como se a galeria, por ela mesma, atribuísse o valor e a importância daquelas obras, como poderíamos dizer, voltando à nossa alegoria, que a grade curricular apresenta o sentido e a importância dos saberes que ela enquadra.

\section{Tempo e espaço já percorridos - Percurso realizado}

Em recente evento de pesquisadores do ensino de história, as discussões sobre currículos estiveram fortemente associadas à formação de professores, demonstrando uma guinada em relação aos debates anteriores, ${ }^{3}$ nos quais a preocupação maior era a de problematizar conteúdos e formas de pesquisas em currículo e ensino, e que eram, além disso, profundamente marcadas por estudos sobre as políticas educativas, especialmente em relação ao conjunto dos documentos curriculares (propostas, diretrizes, parâmetros etc.). Isso certamente produziu ansiedade em relação ao currículo dos cursos de história do país e também em relação

3 Nos outros encontros do ENPEH - Encontro Nacional dos Pesquisadores em Ensino de História, as questões curriculares estiveram presentes com destaque em relação aos movimentos de construção dos textos curriculares e de pesquisa das práticas relativas à aplicação desses textos, nas escolas e nos projetos pedagógicos. 
às reformas educacionais para o ensino fundamental e médio. Destaco, portanto, que me parece haver um diferencial nos encontros atuais de pesquisadores em ensino, e que se tem procurado estabelecer outras possibilidades de olhar.

Para efeito de comparação, no Encontro Nacional dos Pesquisadores em Ensino de História, realizado em Londrina, em 2003, tanto no Grupo de Trabalho sobre Currículo, quanto na mesa-redonda intitulada "Epistemologia e Metodologia: diálogos interdisciplinares na Pesquisa em Ensino de História", percebeu-se um afastamento substancial dos temas de currículo em relação aos programas de ensino, resultante também da preocupação com as práticas curriculares, e nelas, é claro, as práticas do ensino. ${ }^{4}$ Já na edição de 2006 do encontro, a associação de currículo com formação de professores, tendo por base a teoria e a metodologia de pesquisa, no meu entender, permitiu alimentar o debate sobre o caráter interdisciplinar das pesquisas, considerando que os estudos teóricos de currículo estão quase sempre ancorados na grande área da Educação, ao passo que as questões sobre os conteúdos do saber histórico escolar são quase sempre objeto de disputa da História acadêmica.

Desse modo, ao apresentar uma discussão relativa a teorias e métodos de pesquisa em currículo e formação de professores para questões específicas da história escolar, mais do que ampliar os debates sobre os temas, torna visível a presença da área educacional no movimento de configuração dos temas que têm preocupado os historiadores que se empenham nos estudos sobre ensino de história. Arrisco-me a dizer que isso se deve muito à interface que esses mesmos pesquisadores estabelecem em fóruns como Associação Nacional de História (ANPUH) e Associação Nacional de Pós-Graduação e Pesquisa em Educação (ANPEd) e que manifesta aos historiadores a necessidade de compreender o que o campo ou a área educacional têm produzido, e quais parcerias podem ser construídas a partir desse contato. Então, voltando ao caráter alegórico da minha exposição, no tempo e no espaço disponíveis nesses eventos para a abordagem de questões curriculares, vejo a preocupação não somente tática de afirmação dos temas e dos campos de pesquisa, mas também um registro da forma como o currículo está sendo pensado. Do mesmo modo, no quadro de Terniers, percebe-se essa afirmação tática

4 Sobre os trabalhos discutidos, ver o relatório do Grupo de Trabalho em Currículo e Ensino, publicado no livro organizado por Árias Neto (2005, p. 972-973). 
da pintura como um bem cultural, quando a encontramos dispondo de tanto espaço na galeria e tempo entre as atividades do arquiduque.

$\mathrm{E}$, ainda, se consideramos o espaço que o currículo vem assumindo nos referidos encontros, poderia sustentar mais uma vez a alegoria, dizendo que, felizmente, o tema vem gozando de atenção similar àquela definida pela distribuição dos quadros nas paredes do arquiduque. Aparentemente, nada há ali de muito organizado do ponto de vista da arrumação clássica, pois há quadros pelo chão e quadros apoiados uns sobre outros. Mas certamente há uma distribuição ordenada que precisa ser compreendida para entendermos toda a obra. Assim também tem sido a forma como as questões curriculares têm conquistado espaço ou visibilidade entre os historiadores preocupados com o ensino. Acredito que interpretar o que cada pequena abordagem das questões curriculares representa é tarefa para ainda alguns encontros, assim como precisaríamos nos deter em cada obra para sabermos o que é citação de obras do próprio Terniers ou cópias de obras de outros pintores importantes e/ou anônimos mas que compõem o acervo da galeria.

\section{Manutenção das tradições}

Considero ainda que, para o caso dos historiadores que pesquisam o ensino da disciplina, têm aparecido grandes preocupações em relação aos conteúdos e às formas do ensino e que, se é verdade que estamos mais atentos às questões curriculares, estamos também ainda presos demais aos modelos antigos de formação dos professores de história que vêm dos modos das licenciaturas anteriores e nos quais a formação dos professores de história correspondia à formação complementar do bacharelado. Isso não permite que os estudantes de história entrem em contato com saberes específicos do campo curricular, uma vez que na maioria dos cursos as questões curriculares não compõem os programas ou os saberes das disciplinas históricas ou educacionais.

Essa denúncia, já antiga e por demais desgastante, é importante e deve ser sempre trazida à tona, quando pensamos nos entraves que temos para modificar saberes e práticas escolares, bem como para relativizarmos a associação direta entre história e cultura de elite, entre formação histórica na escola e identidade nacional, entre história e ilustração e entre história e cidadania, como se "identidade" e "cidadania" fossem possíveis de serem definidas hoje no singular. O saber histórico é quase sempre entendido, no que diz respeito à escola, aos programas de ensino e ao planejamento 
escolar em forma disciplinar. De modo que predomina a relação entre ensino de história e aula de história, o que, de fato, ainda é muito importante e jamais se esgota. Mas o caso é que pouco se atenta para a forma de construção do saber histórico nas demais atividades e práticas curriculares escolares.

Ademais, a baixa oferta de vagas no ensino superior público, que concentra as pesquisas e que legitima, no Brasil, a inovação científica e cultural, pouco tem contribuído para que as áreas de conhecimento consigam de fato se revolucionarem em relação às tradições, ampliando os debates entre professores e pesquisadores. Dito de outro modo, para se fazer uma educação nacional, tem sido necessário fazer-se escolarização nacional. A ampliação da escolarização, tornando-a central como espaço de aprendizagem da história, expressa a necessidade de ampliarmos o tempo de aprendizagem da história na escola (e quase sempre nos debatemos com as lutas para ampliarmos o tempo de aulas, a quantidade delas e a necessidade de especialização dentro dos currículos escolares). Isso, visto sempre e majoritariamente como algo muito positivo, é bastante questionado pelas teorias curriculares pós-críticas.

A ampliação da quantidade de aulas e um maior tempo dedicado ao ensino disciplinado da história parece conter a expectativa da construção de uma outra realidade, que deveria dar conta dos projetos de uma "nação", fatos para os quais as teorias pós-críticas dos estudos curriculares têm dado especial destaque, uma vez que apresentam as dificuldades da construção de uma identidade fixa em uma época pós-moderna. E a despeito de concordarmos ou não com a pós-modernidade como característica marcante dos tempos atuais, considero importante sinalizar que suas teorias e muitas práticas estabelecidas pelos seus seguidores estão presentes em práticas escolares atuais, realizadas por professores que buscam a inovação de suas práticas com o uso de outras linguagens em suas aulas.

Creio ser essa a maior contribuição que os estudos curriculares contemporâneos trazem para a história ensinada. Os debates que o campo curricular faz sobre o que é o conhecimento e como o poder nele se expressa, ou sobre por que algumas portas só podem ser entreabertas, mas os espaços que elas desvelam não podem ser freqüentados, têm marcado o campo curricular. Dito também de outra forma, o campo curricular enfrentou os debates com as teorias pós-críticas, alargando os debates sobre cultura. E também sobre os sujeitos. Talvez seja essa a 
negação de um determinado tipo de sujeito histórico, ou mesmo da concepção do conceito geral de "consciência histórica", de identidades sociais fixas, mesmo que plurais. Ou mesmo das identidades mestras.

Se pensarmos no quadro de Terniers, diria que ainda estamos mirando a obra com os olhos fixos no quadro maior, que ocupa o centro da exposição, considerando que aquelas pessoas e aqueles cachorrinhos estão em perfeita sintonia com a alusão ao poder e à tradição que expressa a nobreza a que pertence o arquiduque. E apesar da porta entreaberta também estar atraindo o nosso olhar, apenas temos a indicação de que podemos penetrar naquele espaço. E tampouco ainda queremos mostrar ou ver o que há ali...

\section{InTERfaces - Distribuição}

Temos também que considerar, que no ensino de história, saberes históricos e saberes educacionais existem separadamente, mas que também se misturam, se confundem e, claro, não visitamos um campo ou outro apenas para fazer uso de conceitos, embora isso seja necessário às vezes. Não se trata (e isso fica claro ao fazermos pesquisas sobre a história da disciplina ou a história das práticas escolares) de "defender" se o ensino de história ficará melhor (ou foi melhor) por representar uma teoria da história e uma teoria pedagógica (exigindo coerência entre as duas). As pesquisas em história curricular e história das práticas curriculares, assim como as pesquisas sobre a sociogênese das disciplinas escolares e das disciplinas acadêmicas, bem como pesquisas que mostram como as instituições escolares relacionam-se com as prescrições curriculares e modificam a organização de seus projetos pedagógicos, apresentam uma enorme diversidade de sentidos para o ensino da história escolar, o que coloca em cheque até mesmo a clássica relação entre história e cidadania.

Os estudos de currículo, desde que se iniciou o debate sobre a "reconceptualização", e depois de se avançar nas teorias críticas e nos debates sobre diversidades e diferenças, entendidas como uma "relação" e não como marca distintiva dos sujeitos, e ao marcar suas buscas para tentar ampliar os conceitos e valores das "identidades", muito se aproximaram da história, e exatamente por isso incentivaram-se os estudos históricos sobre currículo.

Se a história serve para os estudos culturais do currículo, como então os currículos servem aos estudos culturais do ensino de história? 
Essa pergunta está sendo respondida pelos estudos sobre livros didáticos, currículos e história; quando vemos debates, novamente colocados, sobre patrimônio cultural, memória e currículos de história; quando percebemos a problematização de culturas escolares e ensino de história, além de pesquisas sobre história da implantação de propostas e programas curriculares, tomando por eixo os Projetos Políticos e Pedagógicos escolares.

Trata-se, portanto, de enfatizar que a interface não se faz mais pelas clássicas formas de organização dos saberes da educação, como os fundamentos da educação e as didáticas - e situo isso no contexto educacional brasileiro. Ela se dá porque o ensino de história e o currículo estão em comunicação hoje muito mais pela perspectiva de compreender como se produz o conhecimento histórico escolar e a maneira como ele é legitimado, a que sujeitos e modos de vida referenciam, quais as aprendizagens significativas desses sujeitos, assim como as formas como as prescrições curriculares se realizam nas escolas. Um campo interpela o outro, dialeticamente.

Em nosso quadro de referência, essa imensa alegoria sobre o poder do arquiduque está, ironicamente, abalada, rompendo com uma visão tradicional sobre seu papel e lugar social. Embora ele seja um amante das artes pictóricas, vemos a sua figura pintada na presença de outras pessoas, incluindo o próprio pintor do quadro, que era, nesse caso, um serviçal. $\mathrm{O}$ pintor, entretanto, retrata-se num mesmo plano em que retrata o dono das pinturas, apresentando-se também em meio às obras que são de sua autoria, em pé, atrás da mesa com as esculturas e em trajes de cavaleiro. Essa auto-referência do pintor, que naquele contexto histórico estaria em uma condição social hierarquicamente menor, mostra, portanto, não somente a centralidade e o valor que ele próprio - o pintor - atribui à sua obra, mas a insistência dele para que o observador do quadro reconheça seu trabalho, de maneira que, apesar de manter a alusão ao arquiduque, referenciando-o no nome da obra, há no quadro, um desvio dessa referência tradicional, na medida em que o pintor também aparece, em posição de destaque no quadro.

\section{Personagens e imagens}

Apesar de haver, até aqui, construído uma forma de exposição de idéias que parece sonegar a presença das referências bibliográficas, quero destacar que esse texto foi construído com um grande índice de autores. 
São obras que fazem referência à política curricular e à política do conhecimento. Construí essa parte, tendo por base autores como Hanna Arendt, com o seu clássico $A$ dignidade da política e o livro $O$ que é Política. Tais obras nos ajudam a pensar a relação entre política e produção das suas formas, do fazer e do agir com ela na vida cotidiana, principalmente quando enfatiza que a produção de textos, visando a prescrição regulatória ou mesmo a tomada de posição sobre essas regulações por diferentes grupos sociais, constitui uma maneira de fazer política que conforma os sujeitos e os coloca diante de uma concepção de conhecimento sobre a "realidade". Nesse caso, percebemos sua preocupação em mostrar o que se modifica quando passamos a fazer política produzindo documentos que expressam também projetos futuros. É claro que, para estudarmos documentos curriculares prescritivos, ou mesmo para compreendermos as organizações pedagógicas da escola, que se faz com grande produção de textos, suas obras são forte referência.

Ainda nessa discussão, e já buscando compreender melhor as relações entre políticas, textos e reformas, há obras de Gimeno Sacristán (1998; 1999) e os estudos de Popkewitz (1997 e 1998). Gimeno Sacristán, que tem vasta obra, mas um tanto dispersiva, é essencial também para a retomada dos conceitos de prática curricular e de como fazer pesquisas com ela. No caso mais específico dos currículos de história, afirmo a importância dos textos de Laville (1998; 2005), que se destacam pela interpelação que o autor faz dos momentos significativos das reformas, bem como das temáticas do ensino, tendo como preocupação a discussão sobre os saberes e o conhecimento histórico.

Há Forquin (1993), que merece destaque porque permite repensar as culturas escolares distinguindo-as da cultura da escola, inquirindo o que configura os saberes e o conhecimento escolar e que relações isso tem com as diferentes culturas. E até mesmo nos questiona se estamos pensando nessas coisas. Forquin nos mostra que não é possível estudar os currículos prescritos e a configuração dos saberes escolares descontextualizando o debate entre currículo e gestão escolar. Sua preocupação com o caráter organizacional da escola sempre nos permite procurar os sujeitos nos pontos de suas decisões e escolhas. Em relação ainda às várias possibilidades de pesquisa em currículo e história, ou mais precisamente em história do currículo, ganha peso a obra de Goodson (1995; 2001).

A minha apresentação está especialmente centrada em estudos recentemente publicados por Moreira e Macedo, especialmente no livro 
Curriculo, práticas pedagógicas e identidades (2002), mas também sobre o livro organizado por Moreira, Pacheco e Garcia, denominado Currículo: pensar, sentir e diferir, de 2004.

Com isso, mais do que legitimar com literatura bibliográfica minha reflexão, o que procuro trazer sistematicamente é a preocupação com as pesquisas, tendo por base que há todo um conjunto de referenciais que nos subsidia a pensar currículos em suas mais diferentes manifestações. E, entretanto, para evitar que a palavra currículo e a grande gama de sentidos que ela expressa sejam apenas cenário ou a expressão de uma seqüência de saberes, trago para a mesa de discussões a necessidade de compreendermos também as ferramentas que os estudos curriculares nos apresentam, com suas práticas de pesquisa e com suas idiossincrasias teóricas, a fim de que possamos fazer pesquisas buscando compreender historicamente o que é o conhecimento histórico que ensinamos, como ele foi construído, legitimado, o que e como permanece, ou por que algo é retirado dos programas, dos livros didáticos e da sala de aula.

Reafirmo, portanto, o fato de que, se falamos de algo que já possui uma linguagem singular, temos também que aprender essa linguagem. A reestruturação dos saberes sobre currículo nos mostra a importância de compreendermos sua produção em seus contextos históricos, em meio a suas lógicas de poder e suas narrativas. Mas também mostra a importância de sabermos decodificá-los.

Em retorno ao quadro que nos serve como inspiração para a construção desta apresentação alegórica, trata-se de construir a maneira como podemos olhar para o conjunto e para cada parte de sua composição. Trata-se da relação que temos com a imagem e com os vários pontos de fuga, que nos permite olhá-la junto com os seus detalhes. E de verificar se cada obra, com seus estilos e suas pequenas ou grandes variações, estão ou não assinadas por alguém. Que caminhos percorremos ao vê-la? Como se movimentam nossos olhos?

Por que então resolvi escolher tal imagem para construir esta alegoria, se poderia ter dito isso tudo sem ela? Exatamente porque o que mais me interessa chamar a atenção sobre o currículo é para a sua função narrativa, é para o fato de que metodologicamente não é mais suficiente abordar currículo escolar de história como sinônimo apenas de "conteúdos históricos do ensino", finalidades e formas desse ensino. É também necessário percebê-lo em suas distintas formas, como se apresenta, o que é grade curricular, o que é texto curricular, o que são práticas curriculares, 
como e quem as desenvolve, o que expressam, o que dizem e o que representam. Essa é sem dúvida a nossa maior preocupação de pesquisa. Exatamente porque há uma grande possibilidade de abordagens diferentes sobre currículo e ensino, não me parecia suficiente dar apenas uma definição de currículo. Parece que uma nova imagem se forma a cada vez que fixamos o olhar sobre o tema, assim como nos sentimos estranhamente surpresos, se tentarmos ver e analisar cada pequeno quadro que está na galeria do arquiduque Leopoldo Guilherme.

\section{Referências Bibliográficas}

ARENDT, H. A dignidade da Politica: ensaios e conferências. Rio de Janeiro: RelumeDumará, 2002.

ARENDT, H. O que é Política: fragmento das obras póstumas compilados por Úrsula Ludz. Rio de Janeiro: Bertrand Brasil, 2002.

ÁRIAS NETO, J. M. (Org.). Dez anos de pesquisas em ensino de história. Londrina: Atritoart, 2005.

COSTA CLAVELL, Xavier. Museo del Prado: pintura extranjera. Barcelona: Editorial Escudo de Oro S.A. [s.d.]. (Col. Arte en Espana).

FORQUIN, J. C. Escola e cultura: as bases sociais e epistemológicas do conhecimento escolar. Porto Alegre: Artmed, 1993.

GOODSON, I. F. História del curriculum: la construcción social de las disciplinas escolares. Barcelona: Pomares Corredor, 1995.

GOODSON, I. F. O Currículo em mudança: estudos na construção social do currículo. Porto: Porto Editora, 2001.

LAVILLE, C. A próxima reforma dos programas escolares será mais bemsucedida que a anterior? In: WARDE, M. J. (Org.). Novas politicas educacionais: críticas e perspectivas. São Paulo: PUC, 1998.

LAVILLE, C. Em educação histórica e memória não vale a razão! Educação em Revista, n. 41, p. 13-41, jun. 2005.

MOREIRA, A. F. B.; MACEDO. E. F. (Org.). Currículo, práticas pedagógicas e identidades. Porto: Porto Editora, 2002.

MOREIRA, A. F. B.; PACHECO, J. A.; GARCIA, R. L. (Org.). Curriculo: pensar, sentir e diferir. Rio de Janeiro: DP\&A, 2004.

POPKEWITZ. T. S. Reforma educacional. Uma política sociológica: poder e conhecimento em Educação. Porto Alegre: Artes Médicas, 1997.

POPKEWITZ. T. S. A administração da liberdade; a cultura redentora das ciências educacionais. In: WARDE, M. J. (Org.). Novas politicas educacionais: críticas e perspectivas. São Paulo: PUC, 1998. 
SACRISTÁN, J. G. O currículo: uma reflexão sobre a prática. Porto Alegre: Artmed, 1998.

SACRISTÁN, J. G. Poderes instáveis em educação. Porto Alegre: Artmed, 1999.

\section{Agradecimentos}

Agradeço aos professores Wenceslao Machado de Oliveiria Jr., Milton José de Almeida e Kazumi Munakata pelas contribuições, comentários e críticas que permitiram a construção deste ensaio. As idéias aqui expressas, entretanto, são de minha inteira responsabilidade.

Recebido em: 11/01/07

Aprovado em: 10/04/07 